\title{
Discourse abilities in the structure of intelligence
}

\author{
Anatoly N. Voronin ${ }^{\mathrm{a}}$, Olga M. Kochkina ${ }^{\mathrm{b}^{*}}$ \\ a Institute of Psychology, Russian Academy of Sciences, Moscow, Russia \\ ${ }^{\mathrm{b}}$ Moscow State Univeristy of International Affairs, Moscow, Russia \\ *Corresponding author. E-mail: olkochkina@yandex.ru
}

Background. This article is devoted to empirical research on discourse abilities within the structure of cognitive abilities. Discourse abilities, as well as linguistic abilities, are part of language abilities, but they are directly linked with discourse practices and a certain communicative situation. Discourse abilities allow a person to effectively initiate, keep, expand, and complete the process of communication, using language appropriate to any given situation. These abilities contribute to making communication more effective and achieving mutual understanding between partners, while at the same time they speed up the process of forming an interaction strategy. The empirical verification of the construct "discourse abilities," and the design of original diagnostic tests on them, led us to differentiate linguistic and discourse abilities.

Objective. However, it is not yet clear what place discourse abilities occupy in the structure of cognitive abilities. This is the primary goal of our research.

Method. The design of the study involved group testing (in groups of 15-35 people) using the following methods: a discourse abilities test; a short selection test; a social intelligence test, and short variations of Torrance's and Mednick's tests. In total, 208 people (133 women and 75 men, ages 17 to 21 years) participated in the study, all of them either first year humanities students or high school students from Moscow.

Results and Discussion. The research results revealed that discourse abilities relevantly correlate with the majority of indicators of general and social intelligence and creativity (except non-verbal intelligence). Discourse abilities as part of the structure of cognitive capabilities form a discrete factor, and include relevant components such as verbal and general intelligence and indicators of social intelligence, such as the ability to group expressions. Structures indicative of cognitive abilities varied within the study group, which included people with different levels of discourse abilities. A data structure which conformed to an a priori structure of cognitive abilities was observed only in the group with the medium level of discourse abilities. The group with a low level of discourse abilities mostly showed the aggregation of various indicators of intelligence and creativity, while the group with a high level of discourse abilities showed further differentiation of intelligence types, and the evolution of discourse abilities into a separate factor.

Key words: human cognition, structure of intelligence, psychometrics, creativity, discourse, discourse abilities, communication 


\section{Introduction}

The ability to master language is the vital part of the human mind. Modern societies are estimated to have increasingly engaged verbal intelligence more than non-verbal. Language ability is a constellation of psychological and physiological conditions which ensures the understanding, and adequate reproduction of language signs by the members of the language community (Leontev, 2014). Language abilities determine the ease with which linguistic knowledge and rules of analysis and synthesis of language units are acquired, which allows constructing and analyzing sentences, and using the language system for communication purposes. These abilities contribute to the speed with which a language (both native and nonnative) is mastered, and also to the effectiveness of language use in communication (Kabardov, 2003).

General language abilities are usually subdivided into two components: the linguistic one, which provides for the mastery of the language base, and the communicative one, responsible for successful communication. The former is more essential, as it implies the mastery of language unit models, rules of word changes and collocations, and general vocabulary; the latter, being linked with not strictly linguistic phenomena such as pronunciation, word alteration, and collocation variants, choice of synonyms, etc., is not as binding, and individual peculiarities are possible (Smirnitskii,1981). Factors such as emotional expressiveness, motivation, and the speakers' intentions are often ignored although they define the individuality and communicative aspects of speech, and, consequently, should be part of those studies of discourse that deal with the text immersed in communication (Arutyunova, 1998). Any discourse is simultaneously directed toward the situation in which it occurs (the socio-cultural context sets the rules for conducting conversation and its forms of expression), and toward the person being spoken with (interlocutors communicate, influence each other, and express their opinions, intentions, and views concerning the situation). Discourse is a form of single, partner- and milieucoordinated verbal behavior, supported by a complex knowledge system, depending on the communicative competence of the speakers (Pavlova, 2002). Discourse abilities thus can be defined as abilities to master and realize discursive practices, which are carried out on two levels: as a mental representation of the current social situation, and a representation of a collective subject, obtained through cultural and historical experience (Voronin \& Kochkina, 2008). These abilities allow for the enhanced effectiveness of interaction and more adequate mutual understanding among people in the process of communication; besides, they accelerate the process of defining a strategy for cooperation.

The notion of "discourse abilities" is closely linked with the notion of "communicative competence." Communicative competence is a person's ability to adequately arrange his/her speech in productive and receptive ways, with the help of language usage corresponding to any concrete situation (Zimnyaya, 1989), as well as to combine social, national, and cultural modes, assessments, and values which determine not only a suitable form, but also acceptable content (Vereshchagina \& Kostomarov, 1982).Thus, discourse abilities can be viewed as the operationalized part of communicative competence, which allows the initiation, support, expansion, and conclusion of the process of communication with the help of situationally appropriate verbal means. 
In the course of empirically verifying the "discourse abilities" construct, and developing linguistic and discourse ability diagnostic tests, we succeeded in differentiating linguistic and discourse abilities (Voronin \& Kochkina, 2009). At the same time the discourse abilities scale, designed on the basis of the English language, has pronounced limitations: it is an English version of how to diagnose discourse abilities exercised while studying English as a foreign language. The Russian language method for diagnosing discourse abilities was created at the end of 2013, and is based on data about the modern city communication (Kitaigorodskaya \& Rozanova, 2003). Our research suggests that there are different types of modern communicative space: communication at home and outdoors; purpose-oriented communication and factual communication; weekday communication (holiday communication, working-time communication); and free-time communication. Each communicative area is characterized by a specific form of discourse.

In defining the types of discourse for the developing material of this study, we proceeded from the types of modern city communicative space mentioned above, and took into consideration the psychological peculiarities of everyday discourse (Zachesova \& Grebenshchikova, 2007). The material of the method reflects nine types of discourse: 1) humorous announcements; 2) phone conversations; 3 ) family discourse; 4) business discourse (mostly between employer and employee); 5) teacher-student situational discourse; 6) internet discourse; 7) discourse used in talking with strangers; 8) communicating with people in the service sector; and 9) discourse with friends. Validation of the method revealed that only four generalized types of discourse are verified and valid: discourse when communicating with strangers and acquaintances; discourse when cooperating with relatives and friends; business discourse and internet discourse. These are the types of discourse through which discourse abilities were revealed in our study.

It is possible to define subject areas closely related to the concept of "discourse abilities." The notions that are the closest semantically to "discourse abilities" are the following: "general intelligence," or the successful functioning of the person as a whole; "verbal intelligence," or the ability to carry out verbal mental analysis and synthesis to solve verbal tasks, define notions, determine similarities, etc. (i.e. ability to master the language); and "social intelligence," or the ability to cognize social phenomena (Kochkina, 2009). Actually, the goal of our work is to determine the position of discourse abilities within the structure of such cognitive capabilities.

\section{Method}

\section{Research design and procedure}

Our study of the combined structure of intelligence, creativity, and discourse abilities was carried out in 2013-2014, and involved first-year humanities students from the GAUGN (State Academic University for Humanities) and the Moscow Institute of Economics, Politics and Law, and high school students from Moscow school 539 and gymnasium 1503. The overall number of the participants in the study was 208 (133 women and 75 men, ages 17 to 21 ). The study involved tests in groups of 15 to 35 students using the following methods: a Discourse abilities test; a short selection test adapted by Buzin (Buzin, 1989); a social intelligence test from G. Gilford and 
M. Sullivan adapted by Mikhailova (Mikhailova, 2006); and short variations of Torrance's and Mednick's tests adapted by Voronin and Galkina (Voronin \& Galkina, 1994; Voronin, 1994).

\section{Methods}

The level of intelligence of the participants was estimated with the help of the short selection test adapted by V N. Buzin for fast diagnosis of the following abilities: the ability to summarize and analyze material; flexibility of thinking; inertia in thinking and the ability to change subjects; emotional components of thought and distractibility, speed and accuracy of perception, distribution and concentration of attention; language usage and grammatical correctness; choice of optimum strategy, and spatial imagination (Buzin, 1989).

The study's design demanded that the intellectual productivity evaluation be carried out on three indicators (verbal intelligence, non-verbal intelligence, and an integral indicator) by grouping test points according to the types of the stimulus material. The level of social intelligence was estimated with the help of the adapted version of the G. Guilford and M. Sullivan test adapted by Mikhailova (Mikhailova, 2006). Verbal and non-verbal creativity was diagnosed through short variations of Torrance's and Mednick's tests (Voronin \& Galkina, 1994; Voronin, 1994). Creativity was estimated by several indicators: productivity, originality, uniqueness, and flexibility. The method of diagnosing discourse abilities was based on everyday vocabulary (Voronin, 2014). The afore-mentioned method suggests that the study subjects read a short description of a certain communicative situation and choose the answer most closely corresponding to the described situation. Below we present some examples.

2. You disliked the latest book you read so much that you wrote on the Internet forum: "Disgusting work, this can hardly be called literature." You get the response: "Speculations of an immature person, nothing more can be added."

Your answer is ...

1) Can't catch up with you wise old farts;

2) Every person has his own opinion, so I don't consider mine wrong;

3) That's it-a mature man will never read this garbage;

4) Immature people are illiterate, and this book is really bad, and you, sir, have clearly failed to read it;

5) Try to convince me to change my opinion; I might not have noticed its value;

6) I'm describing my feelings. And I can't like all the books in the world.

5. You answer the phone at home and you hear, "My dear friend, could I please speak to Mr. Ivanov?" You understand that your father is being asked for. You call him saying,

1) Comrade, you are wanted on the phone!

2) Da-a-a-ad!

3) You find out who it is and tell your father, "Dad, Mr. Petrov is calling."

4) One moment...;

5) Mr. Ivanov, this is for you;

6) Dad, it's for you. 
The participant's choice allowed us to draw conclusions about his/her ability to initiate, keep up, develop, and conclude communication, using language that is appropriate to the situation, - i.e., discourse abilities.

\section{Results and Discussion}

Our results were processed with the help of SPSS Statistics 19.0. In the course of the processing, descriptive statistics were estimated, and correlations and factor analyses of the data were carried out. The distribution of variations in discourse abilities turned out to be pseudo-normal, with two additional peaks in the area of low and high values respectively. Discourse abilities turned out to be closely linked with almost all indicators of intelligence and creativity (Table 1).

Table 1. Correlations $\tau$ (tau) Kendall of discourse ability indicators with different types of intelligence and creativity

\begin{tabular}{lc}
\hline \multicolumn{1}{c}{ Indicators } & Discourse abilities \\
\hline Social intelligence. Cartoon Predictions & $.31^{\star *}$ \\
Social intelligence. Expression grouping & $.45^{\star *}$ \\
Social intelligence. Verbal expression & $.19^{\star *}$ \\
Social intelligence. Missing Cartoons & $.29^{\star *}$ \\
Social intelligence. Composite score & $.34^{\star *}$ \\
SST ${ }^{1}$ verbal IQ & $.55^{\star *}$ \\
SSTnon-verbal IQ & 0.04 \\
SSTtotal score IQ & $.22^{\star *}$ \\
SSTpoints reviewed & $.23^{\star *}$ \\
Creativity by Mednick. Productivity & $.23^{\star *}$ \\
Creativity by Mednick. Originality & $.15^{\star *}$ \\
Creativity by Torrance. Fluency & $.16^{\star *}$ \\
Creativity by Torrance. Originality & $.17^{\star *}$ \\
Creativity by Torrance. Elaboration & $.21^{\star *}$ \\
Creativity by Torrance. Flexibility & $.11^{\star}$ \\
\hline
\end{tabular}

${ }^{* *}$ - Correlation significant at $p<.01{ }^{*}$ - Correlation significant at $p<.05$

The discourse abilities test is a method of revealing verbal peculiarities in the cognitive sphere; therefore its correlation with "verbal" indicators of intelligence and creativity is expected to be higher than that with "non-verbal" indicators. This statement seemed to be true with respect to intelligence. Correlation between the indicators of discourse abilities and verbal intelligence is nearly significant at a level

1 SST - short selection test. 
of $\mathrm{p}<.01$, while correlation with non-verbal intelligence is negligible. The highest correlation between the indicators is between verbal intellect and discourse ability. Analysis of social intelligence correlations shows the reverse tendency.

At the same time all the correlations between indicators of discourse abilities and social intelligence indicators are positive and relevant. Correlations with creativity indicators are also positive and significant. The sole indicator that is not linked with discourse abilities is non-verbal intelligence. Analysis of the factor structure of discourse abilities, intelligence, and creativity factors indicates (Table 2) that five major factors can be distinguished: 1) social intelligence, 2) non-verbal creativity, 3) general intelligence, 4) verbal creativity, and 5) discourse abilities. These are most tightly connected with verbal intelligence, general intelligence, and one of the factors of social intelligence - the ability to "expression grouping".

Table 2. Matrix of factor solutions for indicators of intelligence, creativity, and discourse abilities

\begin{tabular}{lccccc}
\hline & \multicolumn{5}{c}{ Component } \\
\cline { 2 - 6 } & $\mathbf{1}$ & $\mathbf{2}$ & $\mathbf{3}$ & $\mathbf{4}$ & $\mathbf{5}$ \\
\hline Discourse abilities & .274 & .254 & -.011 & .137 & .755 \\
Social IQ Cartoon Predictions & .863 & .096 & .104 & .058 & .189 \\
Social IQ Expression grouping & .624 & .113 & .024 & .027 & .538 \\
Social IQ Verbal expression & .485 & -.172 & .243 & .455 & .199 \\
Social IQ Missing Cartoons & .822 & .077 & .099 & .127 & .087 \\
Social IQ Composite score & .911 & .034 & .148 & .111 & .279 \\
SST verbal IQ & .208 & .038 & .391 & -.015 & .776 \\
SST non-verbal IQ & .178 & .097 & .903 & .022 & -.155 \\
SST IQ & .247 & .090 & .866 & .007 & .347 \\
SST points reviewed & -.113 & .189 & .684 & -.091 & .432 \\
Cr Mednick productivity & .122 & .098 & -.252 & .714 & .129 \\
Cr Mednick originality & -.037 & .071 & .183 & .785 & .019 \\
Cr Torrance fluency & .251 & .888 & -.038 & .134 & .094 \\
Cr Torrance originality & .099 & .740 & .291 & .313 & .104 \\
Cr Torrance elaboration & .684 & .378 & -.051 & -.180 & -.124 \\
Cr Torrance flexibility & .018 & .900 & .136 & .042 & .157 \\
\hline
\end{tabular}

The factor structure which was revealed in the analysis basically reproduced the cognitive ability structure, which includes indicators of discourse abilities according to the method based on the English language (Kochkina, 2009). That study revealed four factors: the general intelligence factor; the general intelligence and linguistic ability factor; the social intelligence factor; and the discourse abilities and social intelligence factor. Thus discourse abilities proved to be significantly 
linked with general intelligence, verbal intelligence, and social intelligence ("verbal expression" scale).

The high correlation between discourse abilities and major indicators of different types of intelligence and creativity could be interpreted as bringing out some basic, primary capability, which describes the intellectual sphere as a whole, and comprises both reproductive and productive intelligence. The most adequate and suitable answers of the participants in various communicative situations may be a sign of the kind of rational (intellectual) scheme which they use in daily situations, where rational and reasonable verbal reactions are uncommon. This interpretation of discourse abilities is in line with the concept of practical intelligence identified in R.J. Sternberg's theory of "intellect leading to success" (Sternberg, 2002; Sternberg, Kaufman, 1998). The latter states that practical intelligence predetermines the realization of ideas, and ensures success in a certain social group. It is also expressed in the manifold structure of the factor of discourse ability, which includes indicators of general and verbal intelligence and the factor of social intelligence, shown by "expression grouping".

Consequently, discourse abilities can be psychometrically interpreted as a verbal manifestation of intelligence used to evaluate another person's state, feelings and emotions, and intentions. In other words, it describes the cognitive faculty, which is better known in the literature as "theory of mind". Additionally a person with a high level of discourse abilities can verbalize non-verbal communication components more effectively. Our interpretation of discourse abilities based on the empirical data we obtained suggests that a high level of discourse ability defines the following characteristics of a person:

- Completeness, accuracy, and flexibility in describing a stranger's personality;

- Sensitivity to other people's emotional states in business communication;

- Variety of expressiveness in communication;

- Openness and friendly disposition in communication;

- Sensitivity to feedback in communication, receptivity to criticism;

- High self-esteem;

- Varied and complex description of self-image;

- Exact understanding of how one's own emotional state is perceived by one's communicative partners, which indicates congruence of communicative behavior;

- Adequate situations of self-presentation.

For the present moment the afore-mentioned characteristics are mostly speculations and need further empirical verification. Another, more plausible interpretation of the results may be linked to special features of the sample and the vagueness of the instructions used in testing discourse ability. It did not seem possible to conduct post factum an additional empirical study aimed at revealing the particulars of the subjects' comprehension of the instructions, but additional analysis of the structure of the data obtained could be done. For this purpose the sample was divided into three groups according to the level of discourse abilities they expressed: a group with high indicators (upper quartile), a group with low indicators (lower 
quartile), and the rest - people who were tested with a medium level of discourse ability. Afterwards we did correlational and factor analyses of these groupings.

Correlations between the level of discourse ability, and intelligence and creativity indicators in the different groups, are shown in Table 3.

Table 3. Correlations $\tau$ (tau) Kendall of discourse ability indicators with different types of intelligence and creativity

\begin{tabular}{lccc}
\hline & \multicolumn{3}{c}{ Discourse abilities } \\
\cline { 2 - 4 } & Low level & Medium level & High level \\
\hline Social IQ Cartoon Predictions & $.578^{*}$ & $.357^{\star}$ & -0.057 \\
Social IQ Expression grouping & $.734^{*}$ & $.380^{*}$ & 0.051 \\
Social IQ Verbal expression & $.306^{*}$ & $.403^{*}$ & 0.092 \\
Social IQ Missing Cartoons & $.359^{*}$ & $.359^{*}$ & -0.14 \\
Social IQ Composite score & $.595^{*}$ & $.452^{\star}$ & -0.034 \\
SST verbal IQ & $.325^{*}$ & $.395^{*}$ & -0.159 \\
SST non-verbal IQ & 0.08 & -0.113 & -0.287 \\
SST IQ & 0.226 & 0.139 & $-.301^{\star}$ \\
SST points reviewed & -0.009 & 0.057 & -0.119 \\
Cr Mednick productivity & -0.217 & 0.091 & 0.1 \\
Cr Mednick originality & $.353^{*}$ & $.204^{*}$ & 0.022 \\
Cr Mednick uniqueness & 0.129 & 0.089 & $.242^{\star}$ \\
Cr Torrance fluency & $.656^{*}$ & $-.214^{*}$ & -0.069 \\
Cr Torrance originality & $.647^{*}$ & $-.339^{*}$ & $.618^{*}$ \\
Cr Torrance elaboration & $.400^{*}$ & $.212^{*}$ & -0.191 \\
Cr Torrance flexibility & $.589^{*}$ & $-.412^{*}$ & $-.272^{*}$ \\
\hline & & &
\end{tabular}

* - Correlation significant at $p<.05$

Correlation analysis shows that the group with a high level of discourse abilities has a different structure of correlation interdependencies than the others. A negative correlation between general intelligence and discourse abilities was revealed: there were no connections with social intelligence, but there were significant connections with the major indicators of verbal and non-verbal creativity (with originality and uniqueness), with various indicators of creativity being linked with discourse abilities in different ways. A similar diversity of creativity indicators' ties in various testing situations has also been revealed previously-for instance, when the interconnection of creativity indicators and intelligence of teachers and pupils was studied (Voronin, 2004; Voronin \& Trifonova, 2003). The correlations of various indicators in groups with medium and low level of discourse abilities are more comparable. There were positive interrelations between discourse abilities, and social 
intelligence and verbal creativity indicators. Correlations with general intelligence are non-significant. There are pronounced differences in the case of non-verbal creativity indicators: the group with a low level of discourse ability shows a significant positive correlation, and the group with medium level shows a negative one.

All three groups' data underwent factor analysis by the method of principal components with the consequent Rotation Method: Varimax with Keiser Normalization. Factor analysis results for the group with low discourse abilities are given in Table 4.

Table 4. Matrix of factor solutions for indicators of intelligence and creativity for the sample showing low-level discourse abilities

\begin{tabular}{lccccc}
\hline & \multicolumn{5}{c}{ Component } \\
\cline { 2 - 6 } & $\mathbf{1}$ & $\mathbf{2}$ & $\mathbf{3}$ & $\mathbf{4}$ & $\mathbf{5}$ \\
\hline Discourse abilities & .414 & .701 & & .122 & -.183 \\
Social IQ Cartoon Predictions & .890 & .321 & -.116 & & \\
Social IQ Expression grouping & .533 & .672 & & -.212 & -.340 \\
Social IQ Verbal expression & .813 & .196 & .180 & -.289 & .287 \\
Social IQ Missing Cartoons & .895 & -.105 & .211 & & \\
Social IQ Composite score & .938 & .313 & & -.107 & \\
SST verbal IQ & & .569 & .279 & -.366 & .460 \\
SST non-verbal IQ & .253 & & .883 & & -.138 \\
SST IQ & .266 & .193 & .906 & -.102 & .100 \\
SST points revised & -.145 & .168 & .884 & & .201 \\
Cr Mednick productivity & & -.189 & & & .920 \\
Cr Mednick originality & & .271 & & .844 & -.178 \\
Cr Mednick uniqueness & & .239 & & .861 & .387 \\
Cr Torrance fluency & .261 & .849 & & .257 & -.197 \\
Cr Torrance originality & & .844 & .424 & .228 & \\
Cr Torrance elaboration & .669 & .269 & .304 & .124 & -.229 \\
Cr Torrance flexibility & & .841 & .122 & .299 & .121 \\
\hline
\end{tabular}

Factor analysis of the results revealed five factors, whereby only two of them could be easily interpreted: those of social intelligence and creativity. General intelligence proved to be divided into two factors: the general and non-verbal intelligence factor, and the verbal intelligence factor, which is linked with verbal creativity. The latter is comprised of non-verbal creativity, verbal intelligence, and one of the indicators of social intelligence, the ability to expression grouping. It is the factor on which discourse abilities have the highest loading. At the same time discourse abilities are closely linked with other indicators of social intelligence and 
verbal creativity. The contribution of discourse abilities to the verbal creativity factor is negative.

Factor analysis of the sample showing a medium level of discourse abilities (Table 5) clearly indicates four factors: 1) social intelligence, 2) general intelligence, and 3) non-verbal and 4) verbal creativity. Factor five is comprised of social intelligence and verbal creativity readiness. Discourse abilities with high positive loadings are included in both factors of social intelligence, and their contribution to non-verbal creativity factor is negative.

Table 5. Matrix of factor solutions for indicators of intelligence and creativity for the sample showing medium-level discourse ability

\begin{tabular}{|c|c|c|c|c|c|}
\hline & \multicolumn{5}{|c|}{ Component } \\
\hline & 1 & 2 & 3 & 4 & 5 \\
\hline Discourse abilities & .564 & & -.512 & & .272 \\
\hline Social IQ Cartoon Predictions & .237 & .394 & & .120 & .800 \\
\hline Social IQ Expression grouping & .733 & .114 & & .115 & .218 \\
\hline Social IQ Verbal expression & .767 & .200 & -.107 & .235 & \\
\hline Social IQ Missing Cartoons & .647 & & .150 & & .542 \\
\hline Social IQ Composite score & .632 & .241 & & & .643 \\
\hline SST verbal IQ & .429 & .584 & -.204 & -.182 & .135 \\
\hline SST non-verbal IQ & & .882 & .147 & & \\
\hline SST IQ & .187 & .955 & & & .120 \\
\hline SST points reviewed & .377 & .568 & .211 & -.443 & -.237 \\
\hline Cr Mednick productivity & & & & .866 & .205 \\
\hline Cr Mednick originality & .177 & & & .792 & -.204 \\
\hline Cr Mednick uniqueness & .237 & & .285 & .889 & \\
\hline Cr Torrance fluency & & -.234 & .805 & .204 & .369 \\
\hline Cr Torrance originality & & .240 & .799 & .276 & .104 \\
\hline Cr Torrance elaboration & & & .171 & -.123 & .822 \\
\hline Cr Torrance flexibility & & & .924 & & \\
\hline
\end{tabular}

The results of the high discourse ability sample (Table 6) indicate that discourse abilities constitute a separate factor, which is closely linked with the major indicator of non-verbal creativity - originality. Besides that, five more factors may be distinguished: 1) social intelligence, linked with the non-verbal creativity readiness indicator; 2) verbal creativity, with a high loading of the social intelligence indicator of verbal expression; 3 ) general and non-verbal intelligence, with a negative loading of indicators of verbal creativity elaboration; 4) general and verbal intelligence, with a loading of social intelligence indicators (grouping of expressions); and 5) non- 
verbal intelligence. Discourse abilities have negative loading for two factors: those of non-verbal creativity, and general and non-verbal intelligence.

Table 6. Matrix of factor solutions for indicators of intelligence and creativity for the sample showing high-level discourse abilities

\begin{tabular}{lcccccc}
\hline & \multicolumn{5}{c}{ Component } \\
\cline { 2 - 7 } & $\mathbf{1}$ & $\mathbf{2}$ & $\mathbf{3}$ & $\mathbf{4}$ & $\mathbf{5}$ & $\mathbf{6}$ \\
\hline Discourse abilities & & -.219 & & -.157 & & .889 \\
Social IQ Cartoon Predictions & .953 & & .166 & & .125 & \\
Social IQ Expression grouping & .746 & & -.261 & -.110 & .468 & .187 \\
Social IQ Verbal expression & .305 & & .774 & & .354 & .157 \\
Social IQ Missing Cartoons & .778 & .284 & & .176 & -.241 & -.185 \\
Social IQ Composite score & .953 & & .181 & & .198 & \\
SST verbal IQ & & .286 & & .199 & .783 & -.112 \\
SST non-verbal IQ & & .949 & & .129 & & \\
SST IQ & .122 & .860 & & .207 & .417 & \\
SST points reviewed & .517 & .513 & & .298 & .514 & \\
Cr Mednick productivity & & -.645 & .592 & & -.339 & -.130 \\
Cr Mednick originality & & .462 & .775 & -.162 & .265 & .140 \\
Cr Mednick uniqueness & & & .922 & .153 & -.250 & .149 \\
Cr Torrance fluency & & .271 & & .830 & .268 & .246 \\
Cr Torrance originality & -.115 & .273 & .303 & .262 & & .836 \\
Cr Torrance elaboration & .798 & -.151 & -.367 & & -.346 & -.157 \\
Cr Torrance flexibility & & & & .965 & & -.150 \\
\hline
\end{tabular}

Factor analysis conducted in the groups with different levels of discourse abilities revealed that interconnections between discourse abilities and various indicators of intelligence and creativity in the different groups vary. The factor structure of the data for different groups also varies. These contradictory results can be accounted for in the following way.

First, as a person's intelligence level increases, differentiation within his/her cognitive abilities are enhanced (Voronin, 2004; Druzhinin, 2001). In groups with low and medium discourse abilities, fewer factors are distinguished, and indicators of various types of intelligence and creativity are interlinked to a greater degree. A data structure conforming to an a priori structure of cognitive capabilities is noticeable only in the group with a medium level of discourse abilities. Integration of various indicators of intelligence and creativity is mostly present in groups with a low level of abilities, and groups with a high level of capabilityies reveal further differentiation of intellect types, with discourse ability becoming a separate factor. 
Secondly, the data concerning discourse abilities can be explained by the vagueness of the task to be solved while doing the discourse ability test: the instructions required the choice of an answer most closely corresponding to the given situation. Under conditions of such vagueness, examinees with a low level of discourse abilities might have been trying to solve the given task in a creative way based on their social intelligence. Medium-level examinees might have also based their answers on their social intelligence, but followed non-verbal stereotypes concerning the given situations. The groups with high levels of discourse ability treated the task given by the instructions literally (to choose the answer that corresponds to the situation most precisely), and solved it in a creative way based on their image of the situation.

The diversity of the structure of cognitive capabilities which depend on the level of discourse abilities lets us speak of the specific characteristics of the verbal behavior exhibited by people whose discourse abilities differ. The verbal communication of a person with a low level of discourse abilities will be spontaneous, based on guesses concerning causes of interaction, without a clear view of the partner's aims and motives. Such people's communication is determined by their social experience. The spontaneity of events will direct communication of people with a low level of discourse ability.

People with a medium level of discourse abilities base their communication on a stereotypical view of various communicative situations. The scope of past experience in dealing with communicative situations will account for the success of verbal interaction. Hence communication problems arising from that approach stem from the absence of a holistic vision of the situation, and the impossibility of changing the situation throughout the conversation. Predetermination is an attribute of discourse of people with a medium level of discourse abilities.

When discourse abilities are highly developed, they become one of the most significant factors determining verbal behavior. It might be stated that verbal behavior adequate to the situation appears at this very stage. At the same time such success stems from a situational view of the ongoing communication, and implies creative development of verbal interaction: there might be a change of initiative in the dialogue, and changes in the tempo, content, and purport of the talk in accordance with the situation and the participants' intentions. The possibility of varying the discourse is due to the high level of cognitive capabilityies, and the creative intentions of the interlocutors.

\section{Conclusion}

Discourse abilities significantly correlate with the majority of the indicators of general and social intelligence and creativity (except non-verbal intelligence). Discourse abilities as part of the structure of cognitive ability forms a discrete factor with such relevant components as verbal and general intelligence, and indicators of social intelligence, such as the ability to group expressions. Structural indicators of cognitive capabilities vary in samples with different levels of discourse ability. A data structure which conforms to an a priori structure of cognitive capabilities is observed only in the group with a medium level of discourse abilities. The group with a low level of discourse abilities mostly shows aggregation of various indica- 
tors of intelligence and creativity, while the group with a high level of discourse abilities shows further differentiation of intelligence types, and the evolution of discourse abilities into a separate factor.

\section{References}

Arutyunova, N.D. (1998). Diskurs. In Yazykoznanie. Bolshoi entsiklopedicheskii slovar [Linguistics. Big encyclopedian dictionary] (p. 137). Moscow: Bolshaya Rossiiskaya Entsiklopediya.

Buzin, V.N. (1989). Kratkii orientirovochnyi test [Short selection test]. In Praktikum po psikhodiagnostike. Konkretnye psikhodiagnosticheskie metodiki [Applied handbook on psychological assessment. Psychodiagnostic methods]. (pp.112-126). Moscow: Moscow University Press.

Druzhinin, V.N. (2001). Kognitivnye sposobnosti: struktura, diagnostika, razvitie [Cognitive abilities: structure, diagnostics, development]. Moscow.

Kabardov, M.K. (2003). Kommunikativnye i kognitivnye sostavlyayushchie yazykovykh sposobnostei (individualno-tipologicheskii podkhod) [Communicative and cognitive components of language abilities (individual-typological approach)]. (Doctoral dissertation). Psychological Institute of the Russian Academy of Education, Moscow.

Kitaigorodskaya, M.V., \& Rozanova, N.N. (2003). Sovremennoe gorodskoe obshchenie: Tipy kommunikativnykh situatsii I ikh zhanrovaya realizatsiya (na primere Moskvy) [Modern urban communication: types of communicative situations and their genre realization (on the example of Moscow)]. (pp. 103-120). Sovremennyi russkii yazyk: Sotsialnaya I funktsionalnaya organizatsiya. Moscow: Yazyki Slavyanskoi Kultury.

Kochkina, O. M. (2009). Struktura i dinamika yazykovykh sposobnostei v diskursivnoi praktike [Structure and dynamics of language abilities in discourse practice]. ( $\mathrm{PhD}$ dissertation). State Academic University of Humanities, Moscow.

Leontev, A.A. (2014). Slovo v rechevoi deyatelnosti [Word in speech activity]. Moscow: URSS. (Original work published 1965)

Mikhailova, E.S. (2006). Test J. Guilforda i M. Sullivana. Diagnostika sotsialnogo intellekta.Metodicheskoe rukovodstvo [Guilford and Sullivan's test. Methodical guide]. Saint Petersburg: IMATON.

Pavlova, N.D. (2002). Kommunikativnaya paradigma v psikhologii rechi i psikholingvistike [Communicative paradigm in speech psychology and psycholinguistics]. In N.D. Pavlova 9Ed.), Psikhologicheskie issledovaniya diskursa [Psychological research of discourse]. (pp. 7-17). Moscow: PerSe.

Smirnitskii, A.I. (1981). Objektivnost sushchestvovaniya yazyka [Objectivity of language existence]. Istoriya sovetskogo yazykoznaniya. Nekotorye aspekty obshchei teorii yazyka: Khrestomatiya [The history of Soviet linguistics. Some aspects of the general theory of language: A reader]. (pp. 64-72). Moscow: Vysshaia Shkola.

Vereshchagina, E.M., \& Kostomarov, V.G. (1983). Yazyk I kultura: Lingvostranovedenie v prepodavanii russkogo yazyka kak inostrannogo [Language and culture: Linguistics in teaching Russian as a foreign language]. (p. 257). Moscow: Russkii Yazyk.

Voronin, A.N. (2014). Metodika diagnostiki diskursivnykh sposobnostei na material povsednevnoi leksiki [Methods of diagnosing discourse abilities basing on everyday vocabulary material]. Eksperimentalnaya psikhologiya [Experimental Psychology], 7(2), 94-112.

Voronin, A.N., \& Galkina, T.V. (1994). Diagnostika verbalnoi kreativnosti (adaptatsiya testa Mednika) [Diagnostics of verbal creativity (adaptation of Mednick's test)]. In A.N. Voronin 
(Ed.), Metody psikhologicheskoi diagnostiki [Methods of psychological diagnostics]. (pp. 4081). Moscow: Institute of Psychology, Russian Academy of Sciences.

Voronin, A.N. (2004). Intellekt $i$ kreativnost v sovmestnoi deyatelnosti [Intelligence and creativity in joint cooperation] (Doctoral dissertation). Institute of Psychology, Russian Academy of Sciences, Moscow.

Voronin, A.N. (1994). Diagnostika neverbalnoi kreativnosti (kratkii variant testa Torrensa) [Diagnostics of nonverbal creativity (abridged version of Torrance's test)]. In In A.N. Voronin (Ed.), Metody psikhologicheskoi diagnostiki [Methods of psychological diagnostics]. (pp. 5-40). Moscow: Institute of Psychology, Russian Academy of Sciences.

Voronin, A.N., \& Kochkina, O.M. (2008). Diskursivnye i lingvisticheskie sposobnosti v structure intellekta cheloveka [Discourse and linguistic abilities in human intelligence structure]. Psikhologiya. Zhurnal Vysshei Shkoly Ekonomiki [Psychology. Journal of the Higher School of Economics], 2, 124-132.

Voronin, A.N., \& Kochkina, O.M. (2009). Struktura yazykovykh sposobnostei v protsesse osvoeniya diskursivnoi praktiki [Discourse abilities structure in the process of mastering discourse practice]. Eksperimentalnaya psikhologiya [Experimental Psychology], 2(3), 92-110.

Voronin, A.N. \& Trifonova, I.G. (2003). Sootnoshenie skhodstva/razlichiya lichnostnykh osobennostei uchitelya I uchenika s kreativnostyu uchashchikhsya [Correlation of similarity/differences of personal peculiarities of teacher and pupil with pupils' creativity]. Psikhologicheskiy zhurnal [Psychological Journal], 24(6), 77-85.

Zachesova, I.A., \& Grebenshchikova, T.A. (2007). Vzaimootnosheniya sobesednikov $v$ dialoge [Interlocutors' relationships in a dialogue]. In N.D. Pavlova \& I.A. Zachesova (Eds.), Situatsionnaya i lichnostnaya determinatsiya diskursa [Situational and personal determination of discourse]. Moscow: Institute of Psychology, Russian Academy of Sciences.

Zimnyaya, I.A. (1989). Psikhologiya obucheniya nerodnomu yazyku [Psychology of teaching a foreign language]. Moscow: Russkii Yazyk. 